\title{
EFFECT OF AN IUCD ON AN ENDOMETRIAL RESPONSE TO STEROID HORMONES IN THE RAT
}

\author{
K. BROWN-GRANT \\ Department of Human Anatomy, South Parks Road, Oxford
}

(Received 29th April 1968)

\begin{abstract}
Summary. The presence of a silk thread in the lumen of the upper half of one horn of the uterus of the rat renders that horn sterile. The raised uterus-plasma concentration for radio-iodide that normally occurs on Day 3 of pregnancy is abolished by such a thread placed unilaterally; the control horn shows a normal response. The increase in the uterus-plasma ratio for ${ }^{131} \mathrm{I}$ produced by the administration of progesterone to ovariectomized rats is significantly reduced, but not abolished, in a uterine horn carrying a thread. The inhibition by oestrogen of this response to progesterone is enhanced by the presence of a thread. Changes in the radio-iodide concentration ratio may provide a convenient model system for studies on the mechanism of action of an IUCD in the rat.
\end{abstract}

\section{INTRODUCTION}

A raised uterus-plasma $(\mathrm{U} / \mathrm{P})$ concentration ratio for radio-iodide is observed on Days 3 and 4 of pregnancy or pseudo-pregnancy in the rat or may be induced by the injection of progesterone; the raised ratio for the whole uterus is due to a high concentration of isotope in the superficial epithelial cells of the endometrium (Brown-Grant, 1965, 1966a; Brown-Grant \& Rodgers, 1967). The observation that local inhibition of this response to progesterone could be produced by injection of oil or saline into an isolated segment of the uterus (Brown-Grant, 1967) prompted a study of the possible local effects of an IUCD on this response in the rat.

\section{MATERIALS AND METHODS}

The animals used were female Wistar rats from a closed colony, 170 to $230 \mathrm{~g}$ body weight. Operations were performed under Avertin (tri-bromethanol plus amylene hydrate) anaesthesia. One uterine horn was exposed and using a small straight needle, a thread (Ethicon Mersilk, Braided Silk Suture, size 3/0) was placed in the lumen. The point of entry was on the antimesometrial surface of the uterus about $0.5 \mathrm{~cm}$ below the utero-tubal junction. The thread was passed down the lumen for 1.5 to $2.0 \mathrm{~cm}$ and then brought out on the antimesometrial surface and tied in a loose loop as shown in Text-fig. 1, care being taken not to 
distort the uterus. Bilateral ovariectomy was carried out immediately after the insertion of the thread in some experiments.

Vaginal smears were taken daily from intact rats and they were placed with males of proven fertility at pro-oestrus 4 to 10 days after inserting the thread. Mating was confirmed by the finding of spermatozoa in the smear next morning and this was taken as Day 0 of pregnancy. Ovariectomized rats were used 7 to 10 days after operation. They received 1.25 or $2.5 \mathrm{mg}$ of progesterone (Organon Laboratories) in oil, subcutaneously, $24 \mathrm{hr}$ before killing. In other experiments oestradiol benzoate injection in oil (British Drug Houses) was given, intramuscularly, $16 \mathrm{hr}$ before the injection of progesterone.

The uterus-plasma $(U / P)$ and oviduct-plasma $(\mathrm{O} / \mathrm{P})$ concentration ratios for radio-iodide were determined $2 \mathrm{hr}$ after the intramuscular injection of $5 \mu \mathrm{c}$ of carrier-free $\mathrm{Na}^{131}$ I. Details are given by Brown-Grant (1965, 1966a, 1967). In the present experiments, each horn was divided into an upper and a lower portion (with and without thread in the case of the experimental horn) and U/P ratios determined separately (Text-fig. 1). Values are given in the text and Text-figures as group means \pm S.E. and statistical significance of differences was examined by means of the $t$ test. Not significant indicates a value for $P$ of 0.05 or greater.

\section{RESULTS}

Efficiency of the thread as an IUCD

Six rats with a thread in one horn of the uterus inserted as described were killed between Days 9 and 15 of pregnancy. Implantation sites of the expected size were found in the control horn of all animals (five, six, six, six, eight and eight sites respectively). In no case was there any trace of implantation sites in any part of the horn with a thread inserted, though CL of pregnancy were present in the ovary on that side in all instances.

\section{Effect of the thread on ${ }^{131} I$ ratios on Day 3 of pregnancy}

Concentration ratios were determined on five rats on Day 3 of pregnancy and the results are shown in Text-fig. 1. No evidence of a raised U/P ${ }^{131} I$ ratio on the side containing the thread was obtained either in the upper half that had contained the thread or in the lower half. The calculated value for the experimental horn as a whole $(0 \cdot 65 \pm 0.02)$ was not significantly different from the mean value $(0.64 \pm 0.02)$ observed in thirty-five non-pregnant rats (BrownGrant, 1965). The mean value for the control side $(3 \cdot 12 \pm 0.56)$ did not differ significantly from the mean value for both horns of a group of five normal rats on Day 3 of pregnancy, $4.31 \pm 0 \cdot 52$. The $\mathrm{O} / \mathrm{P}$ ratios on the two sides did not differ significantly.

\section{Effect of the thread on the response to exogenous progesterone in ovariectomized rats}

Six ovariectomized rats with a thread in one horn received $1.25 \mathrm{mg}$ of progesterone; ${ }^{131} \mathrm{I}$ ratios were determined $24 \mathrm{hr}$ later and the results are shown in Text-fig. 2 and in Table 1 . The mean value for the experimental horn $(1 \cdot 21 \pm$ $0 \cdot 15)$ is significantly lower than that of the control horn $(P<0.02)$, but sig- 
nificantly higher $(P<0.01)$ than the mean value for both horns of six ovariectomized rats without threads that did not receive progesterone $(0.51 \pm 0.02)$. The inhibitory effect is more marked in the upper, thread-containing portion of the horn and the difference between the U/P ratios for upper and lower portions of the threaded horn is statistically significant $(P<0.05)$. The $\mathrm{O} / \mathrm{P}$ ratios on the two sides again did not differ significantly. The response of the control horn is not significantly different from the mean value of $2.68 \pm 0.38$ for both horns in six ovariectomized rats without threads treated with $1.25 \mathrm{mg}$ of progesterone.

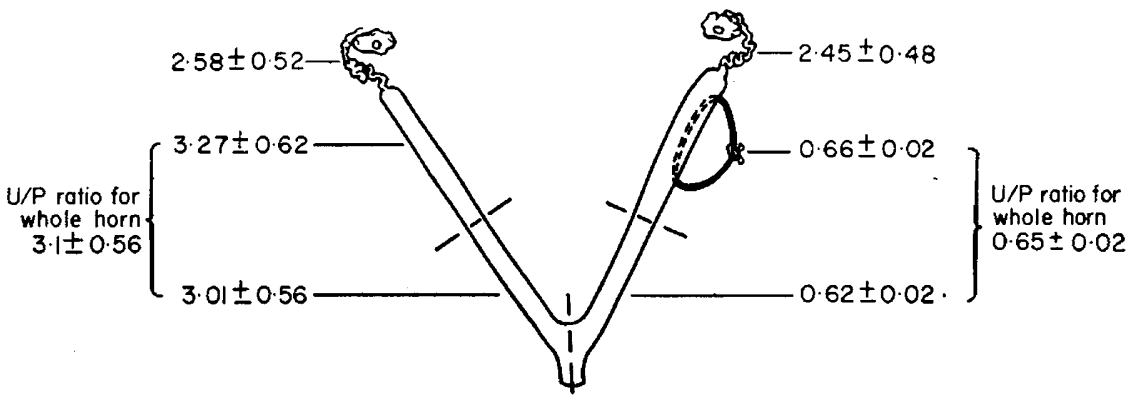

TexT-FIG. 1. Oviduct-plasma (O/P) and uterus-plasma (U/P) concentration ratios for radio-iodide on Day 3 of pregnancy in five rats with a thread in one horn of the uterus. In this and in Text-fig. 2 the values given are means \pm S.E.

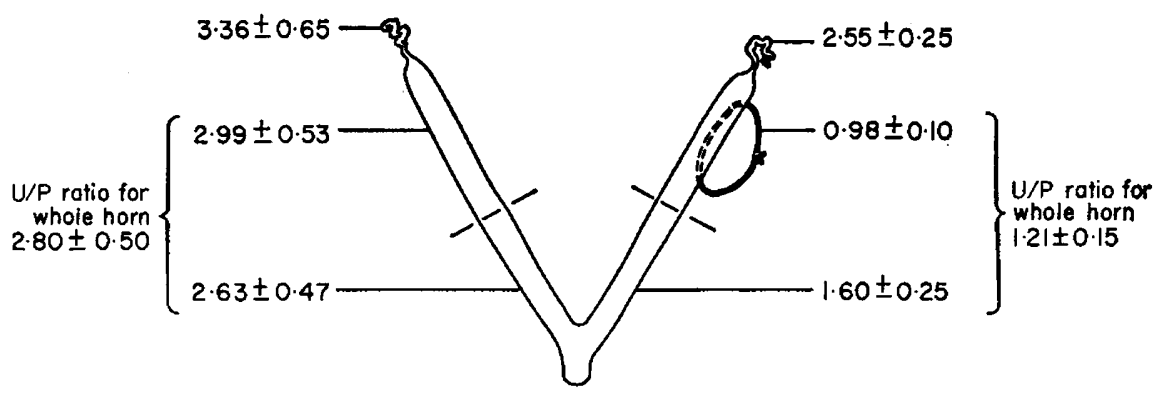

Text-FIG, 2. $\mathrm{O} / \mathrm{P}$ and $\mathrm{U} / \mathrm{P}$ ratios in six ovariectomized rats with unilateral threads that received $1.25 \mathrm{mg}$ of progesterone s.c. $24 \mathrm{hr}$ before killing.

Inhibition of the $U / P$ response, though definite, was less complete in this experiment than in the experiment on rats killed on Day 3 of pregnancy. One possible explanation is that the presence of a thread not only reduces the response to progesterone but, in addition, sensitizes the endometrium to the action of oestrogen which is known to inhibit this particular response to progesterone (Brown-Grant, 1967). Experiments were carried out to test this hypothesis. Six ovariectomized rats with a thread in one horn received $2.5 \mathrm{mg}$ of progesterone only, and other animals received oestradiol benzoate $16 \mathrm{hr}$ before the injection of $2.5 \mathrm{mg}$ of progesterone. In unpublished experiments, this time relationship has been found to achieve the maximal inhibition of progesterone action. The results are given in Table 1 . 
Experiment 2 requires little comment; values for the threaded horn are significantly below those for the control $(P<0 \cdot 001)$, but higher than the values for untreated ovariectomized rats $(P<0.001)$. Inhibition is greatest in the upper half of the threaded horn and the difference between the $U / P$ ratio of upper and lower portions was significant in this experiment $(P<0 \cdot 001) . \mathrm{O} / \mathrm{P}$ ratios on the two sides do not differ significantly.

Oestrogen at a dose level of $1 \mu \mathrm{g}$ had a marked effect on the response to progesterone (Exp. 3, Table 1). All values were significantly $(P<0 \cdot 01)$ below the corresponding values for animals receiving progesterone alone (Exp. 2).

The mean U/P ratios for the whole horn, control or experimental, were not significantly different from the mean value for six untreated, ovariectomized rats $(0 \cdot 51 \pm 0 \cdot 02)$. Although values for the control and treated horns do not differ significantly, values for the experimental horn are somewhat lower.

\section{TABLE 1}

EFFECTS OF PROGESTERONE ALONE OR PREGEDED BY THE INJECTION OF OESTRADIOL BENZOATE 16 HR EARLIER ON U/P AND O/P RATIOS FOR RADIO-IODIDE IN OVARIEGTOMIZED RATS

\begin{tabular}{|c|c|c|c|c|c|c|c|}
\hline \multirow{2}{*}{$\begin{array}{c}\text { Exp. } \\
\text { no. }\end{array}$} & \multirow{2}{*}{$\begin{array}{c}\text { Dose of } \\
\text { progesterone } \\
(m g)\end{array}$} & \multirow{2}{*}{$\begin{array}{c}\text { Dose of } \\
\text { oestradiol } \\
\text { benzoate }(\mu g)\end{array}$} & & \multirow{2}{*}{$O / P$ ratio } & \multicolumn{3}{|c|}{$U / P$ ratio } \\
\hline & & & & & Upper half & Lower half & Whole horn \\
\hline 1 & 1.25 & - & $\begin{array}{l}\text { Control } \\
\text { Treated }\end{array}$ & $\begin{array}{l}3.36 \pm 0.65 \\
2.55 \pm 0.25\end{array}$ & $\begin{array}{l}2.99 \pm 0.53 \\
0.98 \pm 0.10\end{array}$ & $\begin{array}{l}2.63 \pm 0.47 \\
1.60 \pm 0.25\end{array}$ & $\begin{array}{l}2 \cdot 80 \pm 0.50 \\
1 \cdot 21 \pm 0 \cdot 15\end{array}$ \\
\hline 2 & $2 \cdot 5$ & - & $\begin{array}{l}\text { Control } \\
\text { Treated }\end{array}$ & $\begin{array}{l}3 \cdot 36 \pm 0.19 \\
2 \cdot 80 \pm 0.19\end{array}$ & $\begin{array}{l}2.87 \pm 0.33 \\
0.92 \pm 0.04\end{array}$ & $\begin{array}{l}2 \cdot 76 \pm 0.26 \\
1 \cdot 92 \pm 0.16\end{array}$ & $\begin{array}{l}2 \cdot 80 \pm 0 \cdot 28 \\
1 \cdot 29 \pm 0.08\end{array}$ \\
\hline 3 & $2 \cdot 5$ & $1 \cdot 0$ & $\begin{array}{l}\text { Control } \\
\text { Treated }\end{array}$ & $\begin{array}{l}0.91 \pm 0.25 \\
0.76 \pm 0.28\end{array}$ & $\begin{array}{l}0.97 \pm 0.45 \\
0.56 \pm 0.04\end{array}$ & $\begin{array}{l}0.85 \pm 0.35 \\
0.57 \pm 0.05\end{array}$ & $\begin{array}{l}0.90 \pm 0.39 \\
0.56 \pm 0.05\end{array}$ \\
\hline 4 & $2 \cdot 5$ & 0.05 & $\begin{array}{l}\text { Control } \\
\text { Treated }\end{array}$ & $\begin{array}{l}2.62 \pm 0.07 \\
1.81 \pm 0.15\end{array}$ & $\begin{array}{l}3.08 \pm 0.26 \\
0.87 \pm 0.05\end{array}$ & $\begin{array}{l}2.57 \pm 0.21 \\
1.69 \pm 0.32\end{array}$ & $\begin{array}{l}2 \cdot 79 \pm 0.22 \\
1 \cdot 21 \pm 0.16\end{array}$ \\
\hline 5 & $2 \cdot 5$ & 0.2 & $\begin{array}{l}\text { Control } \\
\text { Treated }\end{array}$ & $\begin{array}{l}1 \cdot 63 \pm 0.24 \\
1 \cdot 13 \pm 0.28\end{array}$ & $\begin{array}{l}3.01 \pm 0.90 \\
0.64 \pm 0.08\end{array}$ & $\begin{array}{l}2.61 \pm 0.78 \\
0.90 \pm 0.27\end{array}$ & $\begin{array}{l}2.81 \pm 0.84 \\
0.74 \pm 0.15\end{array}$ \\
\hline
\end{tabular}

Values are means \pm S.E. of determinations in six rats in Exps. 1 to 4, and five rats in Exp. 5 .

In the next experiment, a lower dose of oestradiol $(0 \cdot 05 \mu \mathrm{g})$ was injected. The results are given in Table 1, Exp. 4. O/P ratios on the side with a thread were significantly lower in this experiment $(P<0.01)$. The $\mathrm{U} / \mathrm{P}$ ratios for control and experimental horns did not differ significantly from the values obtained in rats receiving progesterone only (Exp. 2) but U/P ratios for both the upper and the lower half of the horn and the mean ratio for the whole horn were significantly lower on the side containing the thread than on the control side.

A dose of $1 \mu \mathrm{g}$ inhibits the response in both horns and a dose of $0.05 \mu \mathrm{g}$ does not affect the uterine response. An intermediate dose of $0.2 \mu \mathrm{g}$ was tested in five rats with the results shown in Table 1, Exp. 5. On the control side, the $\mathrm{O} / \mathrm{P}$ ratio is significantly below the value for rats receiving progesterone only $(P<0.001)$ but $\mathrm{U} / \mathrm{P}$ ratios are not significantly different. On the side with a thread, $\mathrm{O} / \mathrm{P}$ and $\mathrm{U} / \mathrm{P}$ ratios are all significantly lower than the corresponding 
values in rats receiving progesterone only $(P<0.02)$ and the $\mathrm{O} / \mathrm{P}$ and mean $\mathrm{U} / \mathrm{P}$ ratios are not significantly different from the mean values in six ovariectomized rats $(0.84 \pm 0.07$ and $0.51 \pm 0.02)$. This dose of oestrogen did not affect the response to progesterone of the control horn, but the response of the horn with a thread was completely inhibited.

\section{DISCUSSION}

Unilateral sterilization by a thread inserted in one horn of the rat uterus is well established (DeFeo, 1967) and the experiments reported here were performed only as a check on the effectiveness of the technique employed. The mechanism of action of this or any form of IUCD is not established. In the present study, it has been shown that concentration of radio-iodide in the endometrium in response to progesterone, endogenous or exogenous, is abolished or greatly reduced by the presence of a silk thread in the lumen. The effect is most marked in the region of the uterus near the thread but is also present throughout the horn. This is consistent with the suggestion of Psychoyos (1966) that some chemical agent generated in the vicinity of the loop spreads along the lumen to affect the endometrium at a distance from the loop. Partial inhibition of the response of the endometrium to exogenous progesterone was clearly demonstrated, but not abolition of the response as was seen on Day 3 of pregnancy. One difference is that a small amount of oestrogen may be circulating in the pregnant animals and possibly the presence of a thread sensitizes the uterus to the inhibitory action of oestrogen. When oestrogen was given with progesterone to ovariectomized rats, it was clear that the presence of a thread in no way interfered with the inhibitory action of oestrogen on the progesterone-induced increase in endometrial iodide concentration. The overall inhibition of the response by $1 \mu \mathrm{g}$ of oestrogen was so marked that only suggestive evidence of an increased sensitivity to oestrogen on the part of the horn containing a thread was obtained. A dose of $0.05 \mu \mathrm{g}$ reduced the $\mathrm{O} / \mathrm{P}$ ratios but did not significantly alter the uterine response on either side. An intermediate dose, $0 \cdot 2 \mu \mathrm{g}$, did not affect the uterine response on the control side but the response of the horn containing a thread was completely inhibited, suggesting that the sensitivity of the endometrium to this action of oestrogen was increased.

The biological significance of the iodide-concentrating mechanism of the endometrium and its stimulation by progesterone in early pregnancy is unknown (Brown-Grant, 1966a, b), nor is it established that the rat uterus containing a thread is an adequate model for the study of the general problem of the mode of action of an IUCD (Wynn, 1967). The present experiments have shown, however, that a thread will both prevent implantation of blastocysts and modify the endometrial response to progesterone that results in a raised $U / P$ ratio for radio-iodide in the rat while at the same time the inhibition of this response by oestrogen is not prevented and indeed is probably enhanced. Changes in the response of the endometrium to hormonal stimuli could be a possible explanation for the action of an IUCD; $\mathrm{U} / \mathrm{P}$ ratios for radio-iodide are easy to measure objectively and quantitatively and studies on the lines described here may perhaps be of use in exploring this possibility. 


\section{ACKNOWLEDGMENTS}

This work was supported by grants for technical assistance from the Medical Research Council and for research expenses from the Royal Society which are gratefully acknowledged. The work was begun while the author was Locke Research Fellow of the Royal Society and completed while in receipt of an award from the Lalor Foundation, Wilmington, Delaware. My thanks are due to $\mathrm{Mr}$ J. G. Wood, Department of Zoology, Oxford, for his advice on the technique for inserting the threads and to $\mathrm{Mr}$ M. Sherwood for his valuable technical assistance.

\section{REFERENCES}

Brown-Grant, K. (1965) The metabolism of iodide by the thyroid gland and by the uterus during early pregnancy in the rat. F. Physiol., Lond. 176, 73.

Brown-Grant, K. (1966a) Concentration of radioiodide by the uterus of the rat and the relationship to blastocyst implantation. F. Physiol., Lond. 184, 418.

BRown-Grant, K. (1966b) Failure of orally administered perchlorate to affect deciduoma formation or pregnancy in the rat. $\mathcal{F}$. Reprod. Fert. 12, 353.

Brown-Grant, K. (1967) A quantitative study of the effects of progesterone and related steroids on the uterus: plasma concentration ratio for radioactive iodine in the rat. 7. Endocr. 38, 145.

Brown-Grant, K. \& Rogers, A. W. (1967) The sites of concentration of radioiodide in the oviduct and uterus of the ovariectomized rat, under the influence of progesterone. (Abstract). F. Anat. $101,622$.

DeFeo, V.J. (1967) Decidualization. In: Cellular Biology of the Uterus, ch. 8, p. 191. Ed. R. M. Wynn. Appleton-Century-Crofts, New York.

Psychoyos, A. (1966) Effect antidécidualisant d'un corps étranger intrautérin chez la ratte; rôle des sécrétions utérines. C. r. hebd. Séanc. Acad. Sci., Paris, 262, 1742.

WynN, R. M. (1967) Cellular biology of the uterus. Appleton-Century-Crofts, New York. 